http://jmscr.igmpublication.org/home/ ISSN (e)-2347-176x ISSN (p) 2455-0450

crossref DOI: https://dx.doi.org/10.18535/jmscr/v7i12.46

\title{
Hysterectomy Reviewed: Retrospective Analysis of Hysterectomy Cases Perform over a Period of one year in a Regional Institute
}

\author{
Authors \\ Jha Vandana, Panda Subrat, Singh A Santa \\ Department of Obstetrics and Gynaecology, NEIGRIHMS
}

\begin{abstract}
Objective: To review cases of hysterectomy with an aim to improve our health care in gynaecological cases.

Material and Methods: 125 cases of hysterectomy done for gynaecological indications for 2 years in the Department of Obstetrics and Gynaecology, NEIGRIHMS were reviewed and analysed retrospectively.

Result: Most common age group undergoing hysterectomy were between 36 - 45 years age group (46.4\%). Menstrual irregularities in various forms was the most common symptom (56\%) compelling women lastly for hysterectomy. Fibroid remained the favourite indication (29.6\%) followed by DUB. Vaginal route of hysterectomy associated with reduced hospital stay and faster recovery Blood Transfusion was most common complication.

Conclusion: Hysterectomy is widely performed surgery in gynaecological cases for various indications, although it is safe surgery in terms of morbidity and mortality.

Further morbidity associated with hysterectomy can be avoided by deciding role of alternative therapy and selecting appropriate route and time of surgery in each individual case.
\end{abstract}

\section{Introduction}

Hysterectomy is widely performed surgery in gynaecological cases. Hysterectomy is second only to cesarean section as the most frequently performed major operation in United States. ${ }^{1}$

It is done by open method using abdominal and vaginal route commonly or by laparoscopic technique.

Theoretically Hysterectomy is taken as second or third line treatment in various benign gynaecological conditions like fibroid, DUB but practical scenario is different. Our study reviewed Hysterectomy cases for indication to find out role of alternative therapy in practice as done in various other studies.
As Hysterectomy rate is very high, therefore small change in the incidence of surgery or morbidity associated with surgery may affect our women's health at larger level in-terms of cost morbidity and effectiveness. So, this study about various aspect of Hysterectomy may help in improvement of our health care in gynaecological cases leading to overall improvement in our women's health.

\section{Material and Methods}

125 cases of hysterectomy done in Department of Obstetrics and Gynaecology NEIGRIHMS for 2 years were analysed retrospectively for various aspects. 
Exclusion Criteria: Hysterectomy cases done as obstetrical emergency were excluded from the study.

\section{Result}

Table - I $(\mathrm{n}=125)$ Age

\begin{tabular}{|l|c|c|}
\hline Age Group & Number & Percentage \\
\hline $26-35$ Years & 15 & $12 \%$ \\
\hline $36-45$ Years & 58 & $46.4 \%$ \\
\hline $46-55$ Years & 30 & $24 \%$ \\
\hline $56-65$ Years & 12 & $9.6 \%$ \\
\hline $66-75$ Years & 10 & $8 \%$ \\
\hline
\end{tabular}

Most common age group undergoing hysterectomy were between $36-45$ Years as shown in Table - I

Table - II (Symptoms) n $=125$

\begin{tabular}{|l|c|c|}
\hline Symptoms & Number & Percentage \\
\hline Menorrhagia & 22 & $17.6 \%$ \\
\hline $\begin{array}{l}\text { Menorrhagia with Pain } \\
\text { Abdomen }\end{array}$ & 12 & $9.6 \%$ \\
\hline Menometrorrhagia & 36 & $28.8 \%$ \\
\hline SCOPV & 19 & $15.2 \%$ \\
\hline Lump Abdomen & 15 & $12 \%$ \\
\hline Lump Abdomen with Pain & 9 & $7.2 \%$ \\
\hline Chronic Pelvic Pain & 9 & $7.2 \%$ \\
\hline Persistent Vaginal Discharge & 3 & $2.4 \%$ \\
\hline
\end{tabular}

SCOPV: Some Thing Coming Out Pervaginum

Women having menstrual symptoms in $51.2 \%$ cases and in most cases they had already taken some hormonal treatment for various intervals.

Table - III (Indications) $\mathrm{n}=125$

\begin{tabular}{|l|c|c|}
\hline Indications & Number & Percentage \\
\hline Fibroid & 37 & $29.6 \%$ \\
\hline DUB & 32 & $25.6 \%$ \\
\hline Adenexal Mass & 22 & $17.6 \%$ \\
\hline Prolapse & 19 & $15.2 \%$ \\
\hline Adenomyosis & 5 & $4 \%$ \\
\hline Endometriosis & 2 & $1.6 \%$ \\
\hline CIN III & 5 & $4 \%$ \\
\hline Uterine Malignancies & 3 & $2.4 \%$ \\
\hline
\end{tabular}

DUB: Dysfunctional Uterine Bleeding

CIN: Cervical Intraepithelial Neoplasia

Fibroid remained the most common indication followed by DUB. In large number of cases of DUB, patients want hysterectomy refusing conservative therapy to get rid of symptoms.
Table - IV (Type of Hysterectomy) $\mathrm{n}=125$

\begin{tabular}{|l|c|c|}
\hline Type of Hysterectomy & Number & Percentage \\
\hline TAH & 20 & $16 \%$ \\
\hline TAH + BSO & 70 & $56 \%$ \\
\hline VH & 12 & $9.6 \%$ \\
\hline VH with 'A' 'P' Repair & 20 & $16 \%$ \\
\hline Radical Hysterectomy & 3 & $2.4 \%$ \\
\hline
\end{tabular}

TAH: Total Abdominal Hysterectomy BSO: Bilateral Salpingo-Oophrectomy

VH: Vaginal Hysterectomy

A: Anterio Colporrhaphy

P: Posterio Colpoperineorrhaphy

Table - V (Post Operative Hospital Stay in terms of days)

\begin{tabular}{|l|c|}
\hline Types of Hysterectomy & $\begin{array}{c}\text { Mean Hospital Stay } \\
\text { In Terms Of Days }\end{array}$ \\
\hline VH and VH with 'A' 'P' Repair & 5 Days \\
\hline TAH and TAH + BSO & 7 Days \\
\hline Radical Hysterectomy & 12 Days \\
\hline
\end{tabular}

Table - VI (Complications) $\mathrm{n}=125$

\begin{tabular}{|c|c|c|}
\hline Complications & Number & Percentage \\
\hline Blood Transfusion & 24 & $19.2 \%$ \\
\hline Fever & 20 & $16 \%$ \\
\hline Wound Infection & 4 & $3.2 \%$ \\
\hline Paralytic Ileus & 2 & $1.6 \%$ \\
\hline Upper RTI & 6 & $4.8 \%$ \\
\hline Urological Complications & 2 & $1.6 \%$ \\
\hline
\end{tabular}

No mortality was reported in our study.

As blood transfusion was most common complications all cases were seen for preoperative hemoglobin status.

Table - VII (Mean Pre-Operative $\mathrm{Hb} \%$ )

\begin{tabular}{|lc|c|}
\hline & $\begin{array}{c}\text { Mean Pre-Operative } \\
\text { HB\%) }\end{array}$ \\
\hline $\begin{array}{l}\text { Group Having BT } \\
\text { Complication (24 Cases) }\end{array}$ & $9 \mathrm{gm} \%$ \\
\hline $\begin{array}{l}\text { Group Having No BT } \\
\text { Complication (101 Cases) }\end{array}$ & $11 \mathrm{gm} \%$ \\
\hline
\end{tabular}

BT: Blood Transfusion

\section{Discussion}

Hysterectomy was done most commonly in the age group between 36 - 45 years and fibroid remained the most common indications which is comparable to National Value Study where median age of patients was 45 years and DUB was the most common indication. ${ }^{2}$ 
Symptoms moving around the menstrual irregularities.

No mortality was reported in our study while blood transfusion was the most common complications differing from other studies. One apparent reason was per-operative hemoglobin which was low in blood transfusion group as compared to group having no blood transfusion complications. So this complications can be avoided by selecting proper timing of surgery to make pre-operative hemoglobin more than 11 gm\%. As hospital stay and recovery was more good with vaginal hysterectomy every patient should be selected for proper route of surgery. As fibroid and DUB was the major indication to avoid unnecessary hysterectomy there is place of alternative therapy in these cases. In our Institute, only 10 cases of Uterine Artery Embolization was done during this period, so no case control study could be done to measure efficacy of alternative therapy for fibroid at present.

\section{Conclusion}

Hysterectomy is relatively safe surgery widely performed for gynaecological cases, but for lowering the rate of complication complete preoperative evaluation for timing and route of surgery is necessary for every patient. Unnecessary Hysterectomy should be avoided by using alternative therapy whenever possible.

\section{Reference}

1. Karen J Carlson, David H Nichols and ISAAC Schiff, N Engl J Med; 328:856860.

2. The VALUE National Hysterectomy Study: Description of the Patients and Their Surgery, Maresh, M. J. A.; Metcalfe, M. A.; McPherson, Klim; Overton, C.; Hall, V.; Hargreaves, J.; Bridgman, S.; Dobbins, J.; Casbard, A. 